\title{
GESTÃO DAS EMOÇÕES EM CENTRAIS DE ATENDIMENTO TELEFÔNICO
}

\author{
FEELING MANAGEMENT IN CALL CENTERS
}

Recebido em 30.10.2014. Aprovado em 02.09.2015

Avaliado pelo sistema double blind review

DOl: http://dx.doi.org/10.12712/rpca.v9i3.507

\author{
Fabiano José de Morais \\ fabiano.morais@outlook.com \\ Unigranrio, Rio de Janeiro/RJ, BRASIL
}

\section{João Felipe Rammelt Sauerbronn \\ joao.sauerbronn@gmail.com \\ Unigranrio, Rio de Janeiro/RJ, BRASIL}

\section{Josiane Silva Oliveira}

oliveira.josianesilva@gmail.com

Universidade Federal de Goiás, Goiânia/GO, BRASIL

\section{Fernando Nunes Pestana}

fnpestana@gmail.com

Unigranrio, Rio de Janeiro/RJ, BRASIL

\section{Resumo}

O presente artigo tem como objetivo compreender como operadores de centrais telefônicas realizam a gestão de suas emoções ao longo de suas rotinas de trabalho. O referencial teórico utilizado está baseado na proposta de Hochschild (1983) a respeito da gestão das emoções nas organizações e o conceito de trabalho emocional mecanismos de gerenciamento das emoções na vida profissional que têm como efeito a produção de um conjunto de normas e de técnicas de expressão emocional no cotidiano laboral. A coleta de dados foi realizada por meio de entrevistas em profundidade junto a catorze atendentes de telemarketing, sendo oito mulheres e seis homens, que trabalham em dois call centers. As análises das entrevistas foram realizadas com base nas quatro técnicas de gerenciamentos das emoções propostas por Hochschild (1983), sendo estas trabalho corporal, mudança externa, mudança interna e trabalho cognitivo. Os resultados da pesquisa destacam um conjunto de técnicas corporais de manipulação das emoções no trabalho evidenciando não somente efeitos simbólicos, mas, também, materiais do gerenciamento das emoções realizado pelos indivíduos no trabalho cotidiano. Além disso, também destacamos a necessidade de se discutir as dificuldades enfrentadas pelos operadores de telemarketing na realização das atividades

Palavras-chave: Trabalho emocional. Gestão das emoções. Sociologia das emoções. Telemarketing.

\section{Abstract}

This paper aims to understand how call center operators manage their emotions during their work routines. The theoretical framework is based on Hochschild (1983) approach regarding the management of emotions in organizations and the concept of emotional labor - mechanisms of emotions' management during worklife experience that have the effect of producing a set of rules and techniques of emotional expression in the workplace. Data was collected through in-depth interviews with fourteen telemarketing workers in two call centers. The results highlight a number of physical techniques to manipulate the emotions at workplace showing not only symbolic, but also physical effects of emotion management practiced by individuals in the everyday work.

Keywords: Emotion work. Feeling management. Sociology of emotions. Telemarketing 


\section{Introdução}

O objetivo do presente artigo é compreender como o gerenciamento das emoções no trabalho influencia os padrões de comportamento e as regras de sentimentos dos indivíduos que atuam como operadores em uma central de atendimento telefônico. Para tanto, a opção teórica dos autores recai sobre o referencial proposto por Hochschild (1983) a respeito da gestão das emoções nas organizações. Essa abordagem de análise está alinhada à sociologia das emoções e considera as emoções como a "consciência da conexão das experiências corporais dos indivíduos com os seus sentidos" (HOCHSCHILD, 1983, p. 17). Assim, a consciência da cooperação do corpo com uma ideia, pensamento ou atitude constitui a capacidade de ação do sujeito na sociedade (BONELLI, 2003).

Para Hochschild (1983) as emoções não são estados internos (inconscientes) dos indivíduos, mas se originam nas relações sociais, pois elas estão intrinsecamente relacionadas com nossas experiências na sociedade. Hochschild (1983) abre espaço para discutirmos o impacto macrossocial do capitalismo sobre a dimensão microssocial do trabalho. Sua proposta destaca as formas com as quais as emoções são gerenciadas, negociadas e adquirem valor de troca, especialmente nas relações laborais (BONELLI, 2003). Com isso, é possível analisar as formas com que se dão os processos de conversão das emoções em equivalências materiais e simbólicas, a exemplo das indenizações, do salário ou de cargos (COELHO, 2010).

Essa articulação entre emoções e trabalho no atual contexto socioeconômico possibilitou a Hochschild (1983) desenvolver o conceito de trabalho emocional, que se refere aos mecanismos de gerenciamento das emoções na vida profissional. Segundo a autora, o trabalho emocional tem como efeito a produção de um conjunto de normas e de técnicas de expressão emocional no cotidiano laboral.

No presente trabalho, o foco de análise dos autores procura compreender os padrões de comportamento e as regras de sentimento que fazem parte do trabalho emocional desempenhado pelos operadores de telemarketing. As empresas prestadoras de serviços de telemarketing impõem aos funcionários regras rígidas a respeito do tipo e da intensidade da emoção a ser externada pelos operadores em cada momento de suas atividades laborais. Para seguir as regras criadas pela organização os indivíduos passam a ter que separar internamente suas próprias emoções e apresentar comportamentos emocionais compatíveis com o que é esperado de suas funções dentro do call center.

A coleta de dados foi realizada por meio de entrevistas em profundidade junto a atendentes de telemarketing que trabalham em dois call centers. $\mathrm{O}$ suporte oferecido pelas empresas para a realização das entrevistas no ambiente de trabalho dos operadores parece ter inibido a participação de informantes e, ao fim, apenas catorze operadores com diferentes níveis de experiência na função se apresentaram voluntariamente. Os dados recolhidos foram, ainda assim, muito profundos e possibilitaram aumento da compreensão a respeito das técnicas de gestão das emoções. A análise dos dados levou em consideração a proposta teórica de Hochschild (1983) e o objetivo de identificar as técnicas de gestão das emoções praticadas pelos atendentes em suas atividades laborais.

Os resultados da pesquisa destacaram um conjunto de técnicas corporais de manipulação das emoções no trabalho evidenciando não somente efeitos simbólicos, mas, também, materiais do gerenciamento das emoções realizado pelas empresas no cotidiano de trabalho dos indivíduos.

\section{Sociologia das Emoções e Estudos Organizacionais}

As pesquisas sobre emoções dentro dos estudos organizacionais têm sido frequentemente desenvolvidos a partir dos referenciais da psicologia cognitiva ou da psicologia comportamental (SHIER; GRAHAM, 2010). Essas abordagens consideram as emoções como fenômenos individuais e de domínio do inconsciente dos sujeitos, dicotomizando a dinâmica emocional em relação à racionalidade e aos efeitos sociais nas relações de trabalho.

Entretanto, abordagens sociais de estudo das emoções têm capacidade de ampliar o escopo de entendimento do fenômeno emocional como intrínseco às relações sociais (como já apontava MAUSS, 2003) e de constituição das relações de trabalho (FINEMAN, 2006; ROULEU, 2009), formando um campo disciplinar denominado de Sociologia das Emoções. Esse campo disciplinar apresenta uma conceituação própria das emoções: 
A emoção como objeto analítico das Ciências Sociais pode ser definida como uma teia de sentimentos dirigidos diretamente a outros e causados pela interação com outros em um contexto e situação social e cultural determinados. As ciências sociais das emoções partem do princípio de que as experiências emocionais singulares, sentidas e vividas por um ator social específico, são produtos relacionais entre os indivíduos, cultura e sociedade. Em sua fundamentação analítica, vai além do que um ator social sente em certas circunstâncias ou com relação às histórias de vida estritamente pessoal. (KHOURY, 2006, p. 138)

A definição do objeto de estudo da sociologia das emoções apresenta preocupação em compreender a construção coletiva dos sentimentos. O objetivo é investigar os fatores sociais, culturais e psicológicos que encontram expressão em emoções e interatuam na construção das relações sociais (KOURY, 2006). Como afirma Le Breton (2009), não é a 'natureza' dos indivíduos que se exprime através das emoções, mas os elementos que constituem os sujeitos subjetivamente.

No contexto organizacional, Guerardi (2009) afirma que as discussões sobre a dimensão emocional nas relações de trabalho ao invés de focalizar os sujeitos por 'dentro', em busca de uma essência, deveriam também questionar os meios pelos quais as emoções são construídas na dinâmica social das organizações. Yakhlef (2010) assinala essa lacuna teórica em relação à compreensão das emoções no campo dos estudos organizacionais, que atribui uma dimensão inconsciente à emoção, remetendo ao conflito com a racionalidade. Entretanto, ainda para a referida autora, é necessário desconstruir o entendimento das emoções somente como realidades internas e individuais, ou pré-reflexivas e reconhecer: as pessoas sentem em seu ambiente de trabalho.

Assim como falar, pensar, escrever ou trabalhar, em nosso cotidiano também existe a dimensão do emocionar. A raiva, a vergonha, a inveja, a felicidade, dentre outras emoções, são agenciadas nos arranjos sociais e tencionam, também, os processos organizacionais. Ao propormos estudar essa dinâmica buscamos discutir como as emoções podem atuar como dispositivos de controle e de transgressões no cotidiano organizacional contemporâneo. As emoções também podem atuar de forma a sustentar as relações econômicas, como no caso das indústrias de turismo e entretenimento, formando a denominada 'economia das experiências' (ANDRADE, 2009).
Outros estudos como de Álvarez (2011) sobre práticas organizativas, Rezende (2011) sobre o período de gestação nas mulheres, Mansano (2010) sobre a afetividade no trabalho das assistentes sociais, Herzfeld (2009) sobre o embodiment, Ford e Harding (2008) sobre o medo nas conferências na área de Administração e Lutz e Abu-Lughod (1990) sobre o estatuto das emoções nas ciências sociais, têm avançado, por meio de diferentes abordagens e contextos empíricos de pesquisa, no entendimento das emoções como fenômeno social.

No Brasil, as discussões sobre a sociologia das emoções nos estudos organizacionais ainda são incipientes. Exceções são os trabalhos de Flores-Pereira e Cavedon, (2010) sobre a incorporação das emoções, Bulgacov e Vizeu (2010) e Cramer (2003) sobre as emoções nas práticas de pesquisa, Pestana, Sauerbronn e Morais (2010) sobre o trabalho emocional de servidores públicos, Villardi (2009) sobre aprendizagem nas organizações e Oliveira e Cavedon (2012) sobre as emoções nas práticas organizativas.

Para Borges-Andrade e Pagotto (2010) pesquisas recentes na área de psicologia do trabalho têm destacado as emoções como fenômenos microssociais no cotidiano organizacional. Para as autoras, estes tudos concentraram-se nos debates sobre questões relacionadas ao humor, por exemplo, enfatizando debates sobre situações estressantes, dirigentes, equipes, ambiente físico, recompensas e punições destacando como estados afetivos influenciam desempenho e tomada de decisão no trabalho. Vilela e Assunção (2007) destacam como o trabalho emocional nas empresas pode estar relacionado com a dinâmica de adoecimento laboral. Para os referidos autores, elementos do trabalho emocional diagnosticado na pesquisa realizada focalizam a necessidade dos sujeitos moldarem suas emoções no relacionamento com os clientes de forma a operacionaliza os objetivos estabelecidos pela gestão o que, com feito, resulta em queixas de esgotamento e cansaço pelos funcionários.

Mais especificamente no âmbito das relações de trabalho, assim como Vilela e Assunção (2007), uma abordagem de estudos das emoções que tem apresentado relevante ressonância no campo dos estudos organizacionais é aquela proposta por Hochschild (1983). Mesmo tendo sido apresentada há trinta anos, a proposta de Hochschild permanece viva na academia sendo inclusive tema de um sub- 
tema específico no mais recente colóquio do European Group for Organization Studies (EGOS). Em seu estudo seminal (The Managed Heart), Hochschild apresenta um dispositivo teórico que permite a análise de como as emoções são gerenciadas pelos indivíduos no desenvolvimento de seu trabalho, tendo como efeito a construção de normas e de técnicas de gestão das emoções nas organizações. A presente pesquisa recorre à abordagem teórica proposta por Hochschild (1983) para oferecer uma compreensão a respeito da dinâmica emocional no cotidiano de trabalho dos operadores de telemarketing. A proposta de Hochschild é detalhada ao longo da próxima seção.

\section{Trabalho Emocional}

A abordagem teórica de estudos das emoções desenvolvida por Hochschild $(1979 ; 1983)$ discute o impacto social do capitalismo na dimensão microssocial das emoções dos indivíduos, especialmente vinculadas à vida profissional (BONELLI, 2003). Um dos principais conceitos desenvolvidos por Hochschild (1983) sobre as relações emoções e trabalho é o conceito de trabalho emocional, definido com sendo:

Termo que significa gerenciar os sentimentos para criar uma expressão corporal e facial pública; o trabalho emocional é realizado para se obter um salário, portanto, existe um valor de troca. Os sinônimos 'trabalho emocional' ou 'gerenciamento emocional' são usados para se referir às ações feitas no contexto particular, onde esses valores são apresentados. (HOCHSCHILD, 1983, p. 7)

O trabalho emocional requer que sentimentos sejam induzidos ou suprimidos, como forma de sustentação para o semblante externo que produz o estado de mente apropriado aos que solicitaram um determinado serviço. $O$ trabalho realizado pelo prestador de serviços exige uma coordenação da mente e dos sentimentos, mesmo que muitas vezes o trabalhador exponha características emocionais da sua individualidade no momento da sua atividade laboral.

Hochschild (1983) pesquisou as emoções no trabalho em dois casos. O primeiro foi o trabalho dos comissários de bordo e a empresa escolhida foi a Delta Airlines, considerada àquela época uma empresa com elevado padrão de atendimento em vôo e com programas de treinamento mais exigentes. Além disso, a Delta tinha sua sede localizada em um estado onde o sindicato de comissários de bordo não atuava. Dessa forma, estava claro se tratar de uma empresa que demandava muito de seus comissários e atendia a muito poucas de suas solicitações (HOCHSCHILD, 1983, p.13). Hochschild se interessava em estudar as relações entre gênero e trabalho e nessa ocupação homens e mulheres executavam exatamente a mesmo trabalho, no mesmo local, ao mesmo tempo. Além disso, sendo as mulheres maioria na categoria (85\% àquele tempo), os seus problemas como trabalhadoras não seriam confundidos com os problemas de minorias em uma dada ocupação.

Além de estudar os comissários de bordo, cujo trabalho emocional está focado na oferta de uma atmosfera de cordialidade aos passageiros/clientes, Hochschild pesquisou também o comportamento emocional de funcionários cuja função era cobrar os clientes em débito com a empresa. Muitas vezes esse trabalho é visto com desconfiança e raiva por parte dos clientes. Essa função envolve outras manifestações de emoções entre o prestador de serviço e o consumidor (HOCHSCHILD, 1983, p.16).

Os passageiros dos aviões podem escolher em não sorrir, porém os comissários de bordo são obrigados a não apenas sorrir, mas também de certa forma reverter algum quadro de insatisfação do cliente (HOCHSCHILD, 1983, p.20). Os sentimentos adequados para diferentes situações são induções impostas pela própria sociedade, ou seja, a sociedade possui uma expectativa em relação ao que as pessoas devem sentir em determinada situação. Mauss (2003) foi um dos primeiros antropólogos a problematizar as emoções a partir da dinâmica cultural. De acordo com o autor, as expressões das emoções não se resumem tão somente aos aspectos fisiológicos e cognitivos, mas, também, a como socialmente aprendemos a expressar e manifestar nossas emoções. Seu estudo sobre os rituais funerários na Austrália descreve como se aprende a "chorar o morto" (Thrünengruss) naquela sociedade (MAUSS, 2003, p.147).

Sendo assim, há sempre espaços sociais onde se espera que determinados sentimentos sejam expressos, bem como há emoções obrigatórias esperadas dos atores sociais. Nesse contexto, a cultura seria um mecanismo de socialização das emoções e a obrigação e a não espontaneidade das manifestações emocionais seriam 
elementos marcantes de entendimento das relações sociais. Essa abordagem admite que as emoções são concebidas a partir do nível institucional da sociedade. Além de se constituírem a partir da coletividade e se internalizarem nos indivíduos, as emoções atuam como forças coercitivas para garantirem a estabilidade social.

É nesse ponto que o trabalho de Hochschild (1983) avança nos estudos sobre as emoções nas análises organizacionais ao problematizar como no cotidiano de trabalho o gerenciamento emocional é realizado com o objetivo de garantir a estabilidade social nas organizações, aumentar a produtividade e, consequentemente, produzir lucro para as empresas. Ao evidenciar como as empresas interferem na interpretação das emoções dos funcionários, Hochschild (1983) destaca como os sorrisos e os sentimentos "são expropriados do indivíduo e passam a pertencer à organização" (BONELLI, 2003, p. 361). Para isso, Hochschild (1983) aponta a existência de dois tipos de normas:

Quadro 1. Normas de Gerenciamento das Emoções

\begin{tabular}{|c|l|}
\hline Tipos de Normas & \multicolumn{1}{c|}{ Descrição } \\
\hline $\begin{array}{c}\text { Regras de Sentimento } \\
\text { (Feeling Rules) }\end{array}$ & $\begin{array}{l}\text { São aquelas que especificam o que os indivíduos devem sentir em determinada ocasião. } \\
\text { São regras que definem o que é e o que não é apropriado para o convívio social. Essas } \\
\text { regras influenciam a intensidade, a direção e a duração de determinado sentimento. }\end{array}$ \\
\hline $\begin{array}{c}\text { Regras de expressão } \\
\text { (Display Rules) }\end{array}$ & $\begin{array}{l}\text { São regras que determinam quais são as expressões que um indivíduo deve sentir em } \\
\text { determinadas ocasiões, ou seja, são convenções que guiam os indivíduos sobre que } \\
\text { expressões no qual devem mostrar em uma ocasião específica. Por exemplo, chorar em } \\
\text { um velório ou sorrir em uma festa. }\end{array}$ \\
\hline
\end{tabular}

Fonte : adaptado de Hochschild (1983).

Hochschild (1983) afirma que ao seguir tais regras, os indivíduos mudam o seu comportamento e, com isso, a sua aparência externa também sofrerá modificações, para coadunar com as normas. As duas regras apresentam a maneira como a cultura emocional e as ideologias emocionais influenciam em situações particulares. Isso se amplia para o ambiente profissional, onde a divisão de trabalho e a distribuição de poder são capazes de determinar quais são as regras de sentimentos e as regras de expressão esperadas de cada indivíduo. Espera-se que um executivo use um terno, espera-se que um publicitário use roupas casuais ou até mesmo tenha um bom estado de humor.

A autora também analisa como os indivíduos geram as respectivas emoções para que se mantenham adequadas às regras de sentimentos, de expressão e às ideologias emocionais. Hochschild (1983) apresenta algumas técnicas que auxiliam a esse gerenciamento, expostas no Quadro 2.

Quadro 2. Técnicas de gerenciamento das emoções

\begin{tabular}{|c|c|}
\hline $\begin{array}{c}\text { Técnicas de Gerenciamento } \\
\text { das Emoções }\end{array}$ & \multicolumn{1}{c|}{ Descrição } \\
\hline $\begin{array}{c}\text { Trabalho Corporal } \\
\text { (Body Work) }\end{array}$ & $\begin{array}{c}\text { É a alteração psicológica do indivíduo a partir das manifestações de expressão corporal. O } \\
\text { indivíduo busca a partir do controle de suas funções corporais (respiração, por exemplo) } \\
\text { alterarem o estado psicológico em determinadas situações. }\end{array}$ \\
\hline $\begin{array}{c}\text { Mudança Externa } \\
\text { (Surface Acting) }\end{array}$ & $\begin{array}{l}\text { Os indivíduos manipulam as expressões gestuais com o objetivo de tornarem-se capazes } \\
\text { de sentir a emoção no qual os gestos supostamente sinalizam. }\end{array}$ \\
\hline $\begin{array}{c}\text { Mudança Interna } \\
\text { (Deep Acting })\end{array}$ & $\begin{array}{l}\text { Os indivíduos tentam estimular dentro de si a emergência de determinados sentimentos } \\
\text { que levam a sentir emoções que as regras de expressão determinam. Nesse caso, pode- } \\
\text { se exemplificar o momento em que as pessoas se entristecem para mostrar emoções } \\
\text { "corretas" durante um velório. }\end{array}$ \\
\hline $\begin{array}{c}\text { Trabalho Cognitivo } \\
\text { (Cognitive Work) })\end{array}$ & $\begin{array}{l}\text { Os indivíduos evocam pensamentos e ideias associadas a emoções em particular, no } \\
\text { esforço de gerar sentimentos adequados. Pessoas podem pensar no esforço ou na luta de } \\
\text { uma determinada pessoa para melhor encarar as dificuldades do dia a dia. }\end{array}$ \\
\hline
\end{tabular}

Fonte: adaptado de Hochschild (1983) 
Entretanto, o que permite ao funcionário gerir as emoções é a sua carga emocional (Emotional Stamina). Essa carga mantém um determinado sentimento por um tempo. Os funcionários devem encontrar formas de esconder as emoções que emergem dentro de si e expor somente as emoções que eles devem sentir. Para diminuir a tensão entre o que é sentido e o que deve ser externado, os indivíduos acabam aproximando o que eles realmente sentem daquilo que eles fingem sentir (HOCHSCHILD, 1983).

A Gestão das Emoções fica mais evidente quando as emoções ideológicas, as regras de sentimento e as regras de expressão são contrárias ao que o indivíduo está realmente sentindo - o que Hochschild (1983) denominou dissonância emocional, a partir do conceito de dissonância cognitiva. Diante disso, os indivíduos manipulam seus sentimentos e suas expressões para que eles possam mostrar as emoções adequadas em determinadas situações a determinados grupos. Caso exista algum tipo de violação na expressão dos sentimentos por algum desses indivíduos, os demais encarregar-se-ão de lembrar-lhe das regras.

Marques (2010) trouxe contribuição a essas discussão ao apresentar uma reflexão sobre possibilidades e limitações de compreensão da dinâmica do trabalho emocional de juízes e promotores públicos no Estado de São Paulo. De acordo com o referido autor, o ambiente jurídico é socialmente reconhecido como ambiente de profissões ligadas à racionalidade e à racionalização das emoções. Entretanto, ao focar sua pesquisa sobre os temas relacionados à violência e estupro no trabalho jurídico, Marques (2010) destaca que nos discursos sobre as práticas jurídicas dos profissionais entrevistados as mulheres falavam mais sobre as emoções relacionadas ao seu trabalho do que os homens.

Isso evidencia que mesmo em atividades de trabalho consideradas racionais e de racionalização das emoções, a construção social dos sentimentos se torna um aspecto relevante, uma vez que evidencia como as relações de poder e de gênero ainda são marcantes nas relações sociais. Dessa forma, o estudo das emoções se configura como um possível trajeto para os debates sobre o cotidiano de trabalho dos sujeitos, desvelando elementos silenciosos, porém não menos violentos, de relações de poder, de dominação como também de resistência na sociedade e nas relações de trabalho.

\section{Método}

Em relação aos procedimentos metodológicos, foi conduzida uma pesquisa qualitativa que buscou captar e analisar as experiências vividas pelos atores sociais em seus ambientes de trabalho. Os pesquisadores buscaram fazer com que os entrevistados fundamentassem suas experiências em questão com base em seus próprios sentidos, interpretações, atividades e interações, como sugerido por Moreira (2002). A escolha das empresas operadoras de central de atendimento se deu com base no critério de acesso, visto que um dos pesquisadores exercia cargo de gestão em uma das empresas e outro pesquisador teve acesso aos operadores por conta de laços pessoais com uma gestora da empresa.

Os pesquisadores tiveram autorização para entrevistar os funcionários nas instalações da empresa, fora do horário de trabalho, o que ao mesmo tempo facilitou o acesso a alguns respondentes e inibiu a participação de outros. Como a maioria dos operadores de telemarketing entrevistados trabalha e estuda, o acesso fora do ambiente de trabalho era muito dificultado.

Foram realizadas entrevistas em profundidade com catorze operadores, cujas características são apresentadas no Quadro 3:

Quadro 3 . Perfil dos Respondentes

\begin{tabular}{|c|c|c|c|c|c|}
\hline $\begin{array}{c}\text { Entrevistado } \\
\text { (nome fictício) }\end{array}$ & Sexo & Idade & $\begin{array}{c}\text { Tempo de } \\
\text { Empresa }\end{array}$ & $\begin{array}{c}\text { Tempo como } \\
\text { Operador(a) }\end{array}$ & Escolaridade \\
\hline Ana & Feminino & 27 & 10 meses & 17 meses & $3^{\circ}$ grau completo \\
\hline
\end{tabular}




\begin{tabular}{|c|c|c|c|c|c|}
\hline Diana & Feminino & 22 & 15 meses & 30 meses & $3^{\circ}$ grau incompleto \\
\hline Alexandra & Feminino & 20 & 14 meses & 30 meses & $3^{\circ}$ grau incompleto \\
\hline Cléber & Masculino & 32 & 48 meses & 72 meses & $2^{\circ}$ grau completo \\
\hline Lilia & Feminino & 28 & 17 meses & 17 meses & $3^{\circ}$ grau incompleto \\
\hline Marcos & Masculino & 25 & 24 meses & 52 meses & $2^{\circ}$ grau completo \\
\hline André & Masculino & 28 & 18 meses & 18 meses & $3^{\circ}$ grau incompleto \\
\hline Maria & Feminino & 26 & 13 meses & 13 meses & $2^{\circ}$ grau completo \\
\hline Vanessa & Feminino & 25 & 12 meses & 20 meses & $3^{\circ}$ grau incompleto \\
\hline Carlos & Masculino & 25 & 15 meses & 15 meses & $3^{\circ}$ grau incompleto \\
\hline Vilma & Feminino & 27 & 10 meses & 23 meses & $2^{\circ}$ grau completo \\
\hline Sandra & Feminino & 29 & 15 meses & 15 meses & $2^{\circ}$ grau completo \\
\hline Ricardo & Masculino & 26 & 10 meses & 10 meses & $2^{\circ}$ grau completo \\
\hline Marcelo & Masculino & 29 & 15 meses & 24 meses & $3^{\circ}$ grau incompleto \\
\hline
\end{tabular}

Fonte: elaborado pelos autores

As entrevistas foram previamente agendadas com os participantes e tiveram duração média de duas horas. Foi deixado claro aos respondentes que a pesquisa era autorizada pela empresa, mas que os dados não seriam compartilhados com a mesma. Como proposto por Sanders (1982), as entrevistas tiveram como base um roteiro semi-estruturado. Esse roteiro foi construído a partir dos eixos teóricos do gerenciamento das emoções propostos por Hochshild (1983) e foi dividido em três grupos de questões. O primeiro grupo de questões tratou da relação do funcionário com o trabalho e incluía os sentimentos em relação ao trabalho, em relação à rotina de trabalho, à remuneração, ao deslocamento para o local de trabalho e aos impactos do trabalho na vida do entrevistado. O segundo conjunto de perguntas tratou da relação do entrevistado com os clientes e incluiu os sentimentos e experiências vividos durante atendimento, as formas de tratamento de problemas durante o atendimento. $\mathrm{O}$ terceiro bloco de perguntas tratou do ambiente de trabalho com base em questões que focavam na relação entre o entrevistado e seus colegas de trabalho, gerentes e o espaço físico e a tecnologia. As perguntas não tratavam diretamente das normas ou técnicas de gerenciamento das emoções, mas os pesquisadores buscaram explorar esses temas a partir das respostas dadas. Mesmo baseadas em um roteiro previamente estabelecido, as entrevistas foram conduzidas de modo semelhante a uma conversa informal. As entrevistas foram gravadas no formato $m p 3$ e transcritas para a realização das análises.

A análise das entrevistas foi realizada com base no método proposto por Sanders (1982, p.357), que é dividido em três etapas:

i) Descrição do fenômeno do mesmo modo como foi revelado nas transcrições das entrevistas. As transcrições identificam e descrevem as qualidades da experiência e consciência humanas que dão à pessoa sendo estudada a sua identidade;

ii) Identificação de temas ou invariantes que possam surgir das descrições. Os temas referem-se a elementos comuns que aparecem dentro das descrições e entre elas. O que identifica o tema é a sua importância e não a quantidade de vezes em que o mesmo aparece; e

iii) União dos temas em conjuntos de essências que caracterizam a estrutura do fenômeno. 
Durante o processo de análise das entrevistas os pesquisadores procuraram identificar as formas com que operadores de telemarketing realizam suas técnicas de gestão das emoções. Assim, o fenômeno a ser analisado foi definido como algum tipo de experiência vivida, comum aos diversos participantes, como, por exemplo, haver passado por uma ocorrência traumática, sofrer de certo mal, ou ter vivenciado uma situação específica. Os diversos aspectos da experiência, comum a todos os participantes, constituir-se-ão na essência dessa experiência (MOREIRA, 2002), e que será analisada no estudo.

Os relatos foram agrupados e interpretados a partir das normas e técnicas de gerenciamento das emoções apresentadas por Hochschild (1983), que são as bases da orientação teórica desta pesquisa. De forma complementar, foram trazidas impressões a respeito do trabalho dos operadores de telemarketing a partir de seus próprios pontos de vista. Devido a limitações de espaço apenas alguns trechos das falas dos entrevistados são apresentados ao longo da análise das entrevistas.

\section{Análise e Discussões das Entrevistas}

\section{Caracteristicas do Trabalho em uma Central de Atendimento}

A jornada de trabalho do operador de telemarketing é de seis horas diárias. O controle do trabalho realizado na empresa não se inicia somente com o registro de ponto, pois é necessário também fazer um registro eletrônico na própria estação de trabalho. A estação de trabalho de cada operador de telemarketing se caracteriza pelo computador onde o operador realiza as ligações telefônicas. Esse tipo de controle eletrônico garantiria que, de fato, o trabalhador estaria na empresa e fazendo ligações. O registro eletrônico na estação de trabalho faz com que sistemicamente os operadores tivessem condições de fazer as ligações e falar com os clientes.

Alguns entrevistados destacaram o fato das ligações serem disponibilizadas automaticamente na estação de trabalho, sem a necessidade de o operador efetuar ligações de forma manual. Ao término de um contato, em menos de sessenta segundos, outra ligação é disponibilizada para o operador. Isso é evidenciado no relato de Diana de que "[...] existe um discador geral que faz todo o trabalho sozinho [...] quando soa (a entrevistada faz uma onomatopéia de tom telefônico), o cliente já está atendendo". Quando questionada sobre como se sente em relação a esta forma de disponibilização das ligações, Diana afirma:

\begin{abstract}
Quando eu começo a falar com muitas pessoas, fica cansativo. Desgasta. Eu falo muito, muito, muito (...). Na próxima ligação já não tem o mesmo pique por que já cansou na ligação anterior (...). Se o intervalo entre as ligações fosse maior, seria melhor para o estar bem para trabalhar.
\end{abstract}

É essa dimensão técnica de de controle das emoções que Vilela e Assunção (2007) destacam ao afirmarem que o trabalho emocional, tal qual proposto por Hochschild (1983), consite em moldar as emoções nas relações com os clientes em face dos objetivos estabelecidos pela gestão. Por isso, os tempos de ligações e entre os atendimentos aos clientes são padronizados independente do processo de resolução da demanda dos clientes o que, na fala de Diana, resulta em um "desgaste" que tem que ser "compensado" pelos trabalhadores.

Além do controle sobre a presença do operador de telemarketing na estação de trabalho e das ligações feitas por ele, existe um controle para determinar quais são os momentos em que os operadores de telemarketing podem efetuar pausas nos sistemas para deixar de executar as ligações. Essas pausas são dispostas em lei, pela Norma Regulamentar 17 (popularmente conhecida como a NR-17') que regulamenta a necessidade do operador de telemarketing realizar duas pausas de dez minutos em sua jornada de trabalho.

A legislação também determina a necessidade de outra pausa de vinte minutos. Essa seria destinada ao operador poder fazer algum tipo de lanche. Para aqueles que trabalham no turno da manhã, essa pausa é utilizada para almoçar. Excluídas estas pausas regulamentadas, o operador de telemarketing não tem autorização para sair da sua posição de atendimento (PA). Diana descreve a atividade de operador de telemarketing destacando a importância do PA: "A gente entra na empresa sabendo o que tem que ser feito: Sentar, logar, trabalhar e tirar as suas pausas. É isso!". No relato de Marcos, a descrição do controle do trabalho também é enfatizada em relação a posição na PA: 
Eu sento na PA, ligo para os clientes para ofertar cartão de crédito. Fico de frente para o computador seis horas por dia (no momento que o entrevistado diz essa frase, o tom de voz dele muda, mostrando certa insatisfação pelo fato de permanecer seis horas por dia, em frente ao computador, mostrando total incômodo com a monotonia da atividade) Essa é a nossa rotina. Temos horário para chegar, para tirar pausas, para tudo. Somos controlados o

tempo inteiro.

O controle das ligações telefônicas dos operadores na PA inclui um conjunto de orientações denominado de script pelos operadores. Esse script define a fala padronizada dos operadores de telemarketing. Em todas as ligações, é necessário seguir um padrão de início, de desenvolvimento e de desfecho das ligações. O não seguimento deste script, que inclui determinados bordões e jargões explicitados nos conjuntos de orientações, pode trazer prejuízos para os operadores, especialmente nas avaliações para futuras promoções de cargo na empresa.

Le Breton (2009) destca que não é a 'natureza' dos indivíduos que se exprime através das emoções, mas os elementos que constituem os sujeitos subjetivamente. Nesse sentido, a produção de script de atuação pela empresa para a atuação dos trabalhadores destaca as relações de poder estabelecidas nesse contexto que determinam quem, quando e como se deve atuar no cotidiano laboral. Esse processo pode ser considerado como característico do trabalho emocional (HOCHSCHILD, 1983) visto destacarem a instrumentalização dos sentimentos dos sujeitos em determinado contexto e com uma finalidade específica da organização sem considerar o envolvimento dos trabalhadores com as suas atividades laborais.Há nas centrais de atendimento um setor responsável por analisar as ligações feitas pelos operadores de telemarketing denominado setor de qualidade. Adotando um sistema de coletas de ligações aleatórias, o setor de qualidade analisa algumas ligações feitas pelos operadores, com o objetivo de saber se o mesmo está seguindo o que é necessário ser falado e, também, identificar algum tipo de dificuldade de venda. Todos os operadores são analisados, sem exceção. O setor de qualidade segue um padrão de análise da ligação telefônica, que além de pontuar o que deve ou não ser dito, leva em consideração também o modo como o operador de telemarketing atua nas ligações. Dessa forma, o comportamento do operador diante do cliente é avaliado com base no tom de voz dos operadores e nas palavras utilizadas. A atuação do funcionário é analisada com base na forma com a qual sua voz expressa determinadas emoções. Essa análise gera uma pontuação que permite avaliar o desempenho do operador de forma objetiva. $\mathrm{Na}$ escala de 0 a 100, o operador deve ter nota mínima de 85 para que não seja preterido em processos internos de promoção.

\section{Normas e Técnicas de Gerenciamento das Emoções}

Durante as entrevistas, os operadores de telemarketing destacaram que o controle dos momentos em que os mesmos podem realizar as pausas do trabalho causava mal-estar. Isso porque mesmo sendo algo garantido pela legislação trabalhista, os operadores deveriam avisar o motivo da saída da PA. Quando as vendas estão baixas, a necessidade de explicação é ainda maior, de acordo com Ana: "Mesmo com essa lei (NR-17), se a produção estiver ruim, preciso pedir para o supervisor para tirar a pausa". Quando Ana foi questionada sobre os sentimentos que envolvem esse pedido de permissão, ela afirma:

Somos controlados o tempo todo. Sinto-me péssima, às vezes
estou com muita vontade de ir ao banheiro, pode dar um
problema em mim, eu fico como muita sede, isso atrapalha a
minha produtividade. Me sinto mal, angustiada, chateada
e ansiosa. [...] invade a minha privacidade, tenho que ficar
implorando para ir ao banheiro, na frente de todo mundo.

Parece que estou preso ao men PA. Tem que vender. O mundo lá fora não existe, nem eu posso ter vontade própria de nada. (Marcelo)

Nesses relatos fica clara a evidenciação de sentimentos e emoções, como a angústia, mal-estar, ansiedade e constrangimento. Esses sentimentos são gerenciados para que o trabalho de atendente de telemarketing seja realizado. Quando perguntada sobre o que ela fazia para minimizar esses sentimentos, Ana respondeu que simplesmente evitava ao máximo ir ao banheiro, pois o operador deve agir com naturalidade frente às diversas dimensões de controle no trabalho. Além disso, nada pode afetar a produção de vendas dos cartões de crédito. É isso que Andrade (2009) destaca ao afirmar que as emoções também sustentam dinâmicas econômicas em nossa sociedade, pois a produção de diferentes experiências subjetivas também pode ser base das relações de mercado, no caso em discussão sendo o mercado de trabalho. 
Uma estratégia de gestão das emoções frequentemente utilizada pelos atendentes quando se deparam com um momento desagradável na interação com clientes é o trabalho corporal (body work). Os entrevistados disseram que respiram fundo para voltarem a se sentir bem e não responderem de forma áspera ao cliente, destacando a importância das técnicas corporais de gerenciamento das emoções. O exercício de respiração é a técnica mais comum de trabalho corporal indicada nos discursos dos entrevistados:

Por entrar em contato com o cliente e perturbá-los, os clientes dizem que vão processar, que vão fazer e acontecer. Como somos operadores de telemarketing, eles direcionam toda a raiva para cima de nós. Eu tenho que me manter calma e seguir em frente. Eu fico nervosa, fico com raiva, mas eu respiro fundo, conto de um até dez e continuo trabalhando normalmente. (Alexandra)

Eu liguei para um cliente e pelo endereço dele vi que era de classe alta. Quando en falei com ele, ele veio com quatro pedras na mão e desligou o telefone na minha cara. Eu respirei fundo e segui em frente. Estou pronto para a próxima ligação. (Cléber)

Às vezes en escuto até o que eu não devo escutar. As pessoas me xingam (...) Ninguém é de ferro, eu me seguro, desligo o telefone ou, coloco a ligação no mudo, respiro fundo, começo a falar sozinha, desabafo e bola para frente (...) (Ana)

Liguei para o cliente e foi aquela chuva de mal humor. Quando percebi que estava com a voz ficando fraca, me concentrei na respiração. A voz fica mais forte, mesmo que eu tenha que falar mais devagar. (Maria)

A alteração psicológica do indivíduo a partir da expressão corporal, que o leva a sentir algo dentro das regras de sentimento, pode envolver ações de trabalho corporal mais drásticas. $\mathrm{O}$ trabalho corporal também se manifesta através de violência, como forma de extravasar a tensão e a pressão para as vendas e voltar a sentir a emoção correta:

Eu posso citar pessoas próximas, um amigo meu, que é uma pessoa muito tranquila, mas quando está com um cliente dificil, ele comeşa a apresentar um comportamento diferente. Quando um cliente não consegue entender o que ele está passando, esse men amigo apresenta um comportamento incomum: Ele dá soco na PA! Ele chega as via de fato. Dá soco na PA. Ele dá um soco na mesa. (André)
Todo mundo aqui já teve seu dia ruim. Dia de cliente mais grosso, que fala palavrão, que ameaça a gente. Tenho que manter a mesma calma atendendo o cara grosso. Já cansei de ir ao banheiro e dar porrada na porta. (Ricardo)

Hochschild (1983) destaca como as normas de sentimentos (feeling rules) estão relacionadas às técnicas de gerenciamentos das emoções, especialmente àquelas vinculadas ao corpo. Não são somente as expressões faciais, a exemplo de sorrir, que podem ser evidenciadas no estudo das emoções do trabalho, mas o próprio funcionamento biológico do corpo que se tenta gerenciar transformando a dinâmica macrossocial do capitalismo em técnicas que controlam as formas cotidianas de vivenciar o trabalho. Essa perspectiva de análise foi desenvolvida em estudos como os de Foucault (2008) sobre as biopolíticas. Sendo assim, o gerenciamento das emoções é um mecanismo de controle da materialidade e não somente da subjetividade do corpo do indivíduo.

A mudança externa (surface acting) é baseada na manipulação das expressões gestuais de forma a tornarem o indivíduo capaz de expressar e de sentir a emoção no qual os gestos supostamente sinalizam. Entretanto, como não existe um contato visual com os clientes, as expressões gestuais dos operadores de telemarketing são associadas à voz. O tom de voz é um quesito de análise nas ligações realizadas pelos operadores e é monitorado com frequência.

Tudo que o cliente recebe é a minha voz. Tenho que falar de uma maneira que deixe o cliente sem vontade de desligar o telefone na minha cara. Alguns colegas tentam passar bumildade na voz, para que o cliente fique com pena e não desligue. Eu não sou de fazer vozinha. Aprendi a passar confiança na ligação e ter o cliente atento ao que falo. (Vilma)

Preparo minha voz: Sei que o contato telefônico não é agradável para a maioria das pessoas, mas se ouvirem uma voz agradável e en falar de forma clara, o resultado vai ser melhor. (Vanessa)

O trabalho corporal, conforme citado por Hochschild (1983), envolve a alteração psicológica do indivíduo, por meio de manifestações de expressão corporal. Yakhlef (2010) destaca, nesse sentido, que as emoções não se constituem apenas com base em manifestações 
individuais ou do inconsciente dos indivíduos, mas pode ser produzida socialmente como forma de constituição de diferentes contextos sociais. Por isso, o tom de voz não deve deixar transparecer os efeitos da tensão e da pressão sofridos pelos atendentes de telemarketing no desenvolvimento de seu trabalho. Durante o contato telefônico, antes mesmo de saber se o cliente aceitará a proposta do cartão de crédito, Ana diz que se sente muita nervosa. Tenta não apresentar o nervosismo para o cliente, sempre mantendo um padrão de voz que denote segurança:

Tento não demonstrar o nervosismo para o cliente pela voz: Mas o coração acelera, acelera ainda mais quando eu sei que a venda vai acontecer, que o cliente está tendo dúvidas, que ele quer o cartão de crédito, então dá uma ansiedade e nervosismo, mas eu tento não transparecer (...) Penso na necessidade de vender para me controlar.

Para que os contatos telefônicos com os clientes sejam bem feitos é necessário que os operadores conheçam o produto e saibam pronunciar corretamente o nome da empresa, o nome completo de quem está entrando em contato, frases de início de ligação e frases de desfecho. Portanto, os operadores são treinados para realizar suas atividades. Eles consideram que, por não existir o contato direto com o cliente, a ligação telefônica deve ser aproveitada da melhor forma possível. Nos treinamentos ministrados pela empresa de call center, os recém-contratados ouviam diversas ligações nas quais operadores considerados desmotivados e motivados falavam com clientes e aprendiam a identificar o "sorriso na vOz".

No treinamento, antes de iniciar as atividades na operação,
eles falam em praticar o sorriso na voz. Eles dizem que é
preciso encantar o cliente. Eles apresentam exemplos de
uma ligação em que a pessoa entra em contato com o cliente
com uma voz. triste e um exemplo de uma pessoa que fala
com o cliente com o sorriso na voz. Então eles perguntam:
Vocês comprariam algo de uma pessoa que liga para você e
essa pessoa não tem sorriso na voz?! (Marcos)

Em outras situações a gestão das emoções no ambiente de trabalho é realizada através da mudança interna (deep acting) que está baseada na estimulação interna de alguns sentimentos. Esses sentimentos estimulados se sobrepõe àquilo que o indivíduo realmente está sentindo e permitem que o seu comportamento seja adequado (e os objetivos da empresa sejam alcançados). A evocação do sentimento de vitória e orgulho, que é compartilhado por outros, é uma das estratégias de mudança interna utilizadas:

\begin{abstract}
Depois de ficar muito tempo com o cliente no telefone $e$ vender, ver todos comemorando com você, por você, isso é muito legal. O sentimento de vitória fica comigo em várias outras ligações. (Ana)
\end{abstract}

O sentimento de vitória é estimulado e desejado por todos os colegas de trabalho e, dessa forma, a entrevistada Ana opera uma mudança interna de sentimentos (deep acting) que a leva a sentir as emoções que o ambiente de trabalho exige. Em outro caso, o gerenciamento emocional dos atendentes Cléber e André envolve a ideia que o cliente não está reclamando diretamente com o atendente, e sim com a empresa. O discurso de outro operador deixa clara outra estratégia de mudança interna de sentimentos:

\begin{abstract}
Eu sempre procurei ver os dois lados da moeda. Eu procuro entender. Eu sei que é muito complicado, estou com a necessidade de tirar a pausa, eu não posso tirar por que já existem pessoas que estão na pausa, naquele determinado momento, (...) é meio chato na hora, por que às vezes a necessidade é um pouco grande, mas eu entendo a necessidade da empresa em si, por que ela tem que ter uma quantidade de pessoas logadas naquele momento. A empresa precisa cumprir o contrato com a outra empresa para qual ela presta serviço. (Cléber)
\end{abstract}

\begin{abstract}
Na hora eu fico chateado, mas eu procuro botar na cabeça que o problema não é comigo em si, mas sim para o grupo financeiro que eu estou representando. A pessoa não está reclamando de mim, mas sim da empresa que eu estou trabalhando. Eu assimilo, peço desculpas pelo incômodo e cadastro no sistema a recusa do cliente. E sigo em frente. (André)
\end{abstract}

Como se vê, o atendente estimula dentro de si o sentimento que o leva a sentir a emoção correta para a atividade. Mesmo sentindo raiva, os operadores desenvolvem internamente a sensação de quietude e satisfação. Essa manobra permite que o resultado da interação com o cliente não seja mais desagradável. A mudança interna é um mecanismo de gestão das emoções que permite que o atendente atenda às regras de expressão (display rules) e às regras de sentimento (feeling rules). 
A quarta técnica de gerenciamento das emoções proposta por Hochschild, o trabalho cognitivo (cognitive work), é praticada a partir da evocação de pensamentos e ideias que estão associadas a sentimentos adequados para a realização daquele trabalho. Os informantes pensam na necessidade do trabalho, na vontade de crescer na empresa, na troca de função dentro da organização, nas promoções, na necessidade de ganhar dinheiro para pagar a faculdade, etc. Esses pensamentos ajudam a enfrentar o dia longo de trabalho: "Muitos sonhos, muitos objetivos, eu penso nisso tudo para poder estar aqui, todos os dias." (Alexandra, afirmando apegar-se aos seus sonhos para poder trabalhar); "Eu tenho os meus objetivos, eu tenho que ganhar dinheiro (...) eu quero crescer na empresa. Eu fico esperando a oportunidade, participar de um processo seletivo interno, fazer e passar" (Lilia).

Cléber também pratica o trabalho cognitivo relacionando os sacrifícios vivenciados em seu trabalho à realização de sonhos. O operador tenta esquecer a pressão de bater meta, da pressão de vencer, da cobrança por resultados se apegando aos seus sonhos e objetivos:

Eu não deixo esses aspectos negativos influenciarem. Eu tenho sonhos. Eu tenho metas a atingir. Como eu vou realizar os meus sonhos, como en vou realizar as minhas metas? Trabalhando...

No relato de Marcos, é possível observar como as normas de gerenciamento das emoções também são utilizadas pelos sujeitos para velarem o constrangimento que sofrem em seus locais de trabalho. Isso evidencia como mecanismos de dominação e de sujeição vão se estabelecendo no cotidiano do operador de telemarketing que passa a naturalizar tais situações e ativa os mecanismos de trabalho cognitivo (cognitive work):

Eu sou controlado a todo o momento. A todo o momento, tem alguém te vigiando, alguém te controlando, isso me incomoda. Para minimizar isso, eu procuro acatar. Para mim é irrelevante. Já estou acostumado. Pelo tempo que eu tenho de telemarketing (pouco mais de 4 anos e meio), eu já superei essa insatisfação. [...] Para eu mudar isso, eu estou fazendo um curso técnico para mudar de emprego. Penso que en já estou fazendo o curso e que eu vou mudar de área. Eu vou para uma coisa melhor, aumentar a minha renda familiar, melhorar a minha vida. (Marcos)
Os objetivos de crescimento profissional e pessoal servem como suporte para o atendente continuar a fazer as atividades. Mais uma maneira de fazer o trabalho cognitivo e ter condições de realizar o trabalho de maneira positiva. O pensamento evocado promove o surgimento de emoções positivas (orgulho, alegria, felicidade) e estimula o comportamento adequado do operador em atendimento. Mesmo nos casos em que há reclamações por parte do cliente, o trabalho cognitivo é utilizado para que o operador possa orientar seu comportamento. Estas técnicas de gerenciamento das emoções não se restringem ao cotidiano profissional dos operadores de telemarketing. Elas também têm efeito na vida privada dos indivíduos, pois o trabalho cognitivo evoca pensamentos e ideias associadas às emoções em particular no intuito de transfigurar as dificuldades do dia a dia. Portanto, é preciso destacar que as emoções são produções sociais constitutivas das relações de trabalho (FINEMAN, 2006; ROULEU, 2009).

\section{Considerações Finais}

As atividades de prestação de serviços estão baseadas em interações com clientes. O contato permanente entre prestadores de serviços e consumidores desses serviços faz com que organizações prestadoras de serviços estabeleçam padrões de comportamentos e regras de sentimentos a serem externadas no momento da entrega dos serviços. A presente pesquisa teve como objetivo contribuir para o conhecimento a respeito das técnicas de gerenciamento emocional utilizadas pelos operadores de telemarketing. O propósito do estudo consistiu em observar como as técnicas utilizadas pelos operadores em suas atividades laborais se aproximam daquelas propostas por Hochschild (1983). Como vimos, o gerenciamento emocional é desempenhado de várias maneiras, mas sempre com o mesmo propósito: apresentar o padrão emocional e comportamental esperado pela organização no momento de efetuar o contato com o cliente.

Os resultados da pesquisa qualitativa são invariavelmente descritos a partir da orientação dos participantes, em vez de serem codificados em linguagem cientifica ou teórica. $\mathrm{O}$ pesquisador identifica "temas" nos dados e a partir dos temas é desenvolvida uma explicação estrutural (MOREIRA, 2002). Conforme identificado, o gerenciamento 
emocional é desempenhado de várias maneiras, todas elas com o mesmo propósito: apresentar o padrão emocional e comportamental esperado pela organização no momento de efetuar o contato com o cliente, que no caso estudado, refere-se em efetuar o contato telefônico com o cliente de modo afetivo e entusiástico para ofertar os cartões de crédito.

O quadro a seguir apresenta as técnicas utilizadas pelos operadores de telemarketing entrevistados, utilizando os parâmetros expostos por Hochschild (1983):

Quadro 4 . Resumo das Técnicas de Gerenciamento das Emoções Apresentadas pelos Entrevistados

\begin{tabular}{|c|c|}
\hline Técnicas & Descrição \\
\hline $\begin{array}{l}\text { Trabalho Corporal } \\
\text { (Body Worke) }\end{array}$ & $\begin{array}{l}\text { Diante de situações difíceis no contato com o cliente, os entrevistados disseram que realizam diversas ações } \\
\text { com o corpo, com o objetivo de minimizar o momento adverso das ligações e seguir em frente: respirar } \\
\text { fundo para seguir trabalhando, contar de um até dez, socar a PA, socar a porta do banheiro, passar as mãos } \\
\text { nas pernas, balançar as pernas, fechar os olhos, respirar fundo. E seguir com o atendimento. }\end{array}$ \\
\hline \multirow{2}{*}{$\begin{array}{l}\text { Mudança Externa } \\
\text { (Surface Acting) }\end{array}$} & $\begin{array}{l}\text { Mesmo não tendo contato direto com os clientes, pelo simples fato do diálogo ser realizado por contato } \\
\text { telefônico, os entrevistados apontaram a utilização de uma técnica que visa combater a ausência da presença } \\
\text { física. Seria a prática de falar com o cliente com um tom de voz que denotasse afetividade e entusiasmo } \\
\text { com a atividade. Essa vontade de falar com o cliente, de querer vender, da convicção que de fato o cartão } \\
\text { ofertado lhe tratará vantagens, é denominado como sendo 'sorriso na voz'. Esse termo foi cunhado por } \\
\text { todos os entrevistados. }\end{array}$ \\
\hline & $\begin{array}{l}\text { Treinamentos são ministrados pelas empresas, com o objetivo de disciplinar os operadores de telemarketing } \\
\text { no tom de voz adequado a ser utilizado no momento de falar com o cliente. }\end{array}$ \\
\hline \multirow{2}{*}{$\begin{array}{l}\text { Mudança Interna } \\
\text { (Deep Acting) }\end{array}$} & $\begin{array}{l}\text { O atendente estimula dentro de si o sentimento que o leva a sentir a emoção correta para a atividade. } \\
\text { Estimulação interna de sentimentos positivos: vitória, satisfação, quietude. }\end{array}$ \\
\hline & O operador procura entender o lado da empresa, e pensa que a rigidez do controle é necessária. \\
\hline $\begin{array}{l}\text { Trabalho Cognitivo } \\
\text { (Cognitive Work) }\end{array}$ & $\begin{array}{l}\text { Os operadores evocam pensamentos e ideias que estão associadas a sentimentos adequados para a realização } \\
\text { daquele trabalho: crescimento pessoal e profissional, realização de sonhos. }\end{array}$ \\
\hline
\end{tabular}

Fonte: elaborado pelos autores

Com o presente trabalho, esperamos chamar a atenção da comunidade acadêmica nacional para o desenvolvimento de estudos sobre o gerenciamento emocional e comportamental adotados por indivíduos em suas atividades de prestação de serviços. Da mesma forma, esperamos estimular pesquisas a respeito das consequências da gestão das emoções para a saúde dos trabalhadores, para os processos de organizar (FINEMAN, 1998) ou mesmo sobre as questões de gênero (ROULEAU, 2009). Muita atenção tem sido dada às expectativas e necessidades dos clientes de serviços, uma atenção maior pode ser dada ao trabalho dos prestadores de serviços.

Além da comunidade acadêmica, esperamos com essa pesquisa chamar a atenção de gestores, gerentes, diretores, empresários e tomadores de serviços de call center, das dificuldades enfrentadas pelos operadores de telemarketing na realização das atividades. As responsabilidades dos mesmos não ficam somente atreladas em atender os 
clientes da melhor forma possível. Também existe a necessidade de dedicar uma atenção maior às pessoas que executam as tarefas por eles impostas, para buscar a satisfação dos clientes.

Alguns podem afirmar que o gerenciamento emocional é algo que permeia todas as atividades de prestação de serviços. Assim, a ausência de autonomia e o excesso de controle estariam naturalizados em todas essas atividades. Não chegou o momento de revisar o modelo existente? Novos estudos são necessários para que prossigamos essa discussão.

\section{Referências Bibiográficas}

ÁLVAREZ, M. I. F. Além da racionalidade: o estudo das emoções como práticas políticas. Maná, v.17, n.1, 2011, p. 41-68.

ANDRADE, D. P. Economia de experiências: poder emocional e desigualdade afetiva. In: X Congresso Luso-Afro-Brasileiro de Ciências Sociais, Anais... 2009, Braga: CBLABCS, 2009.

BONELLI, M. G. Arlie Russell Hochschild e a sociologia das emoções. Cadernos Pagu, v. 21, p.357-372, 2003.

BORGES-ANDRADE, J. E.; PAGOTTO, C. P. O estado da arte da pesquisa brasileira em Psicologia do Trabalho e Organizacional. Psicologia: Teoria e Pesquisa, v. 26, p. 37-50, 2010.

BULGACOV, Y. L. M.; VIZEU, F. A positividade da emoção na prática da pesquisa nas organizações. Cadernos EBAPE.BR, v. 9, p. 488-509, 2011.

COELHO, M. C. Narrativas da violência: a dimensão micropolítica das emoções. Maná, v.16, n.2, p. 265 285, 2010.

CRAMER, L. Neutralidade científica: conflitos entre uma ação moral ou emocional. In: XXIII Encontro da Anpad, 23, 2003, Atibaia. Anais... Rio de Janeiro: ANPAD, 2003.

DENZIN, N. K; LINCOLN, Y. S. Introduction: entering the field of qualitative research. In: DENZIN, N. K.; LINCOLN, Y. S. (eds.) Handbook of Qualitative Research. London: Sage, 1994.

FINEMAN, S. A emoção e o processo de organizar. In: CLEGG, S. R.; HARDY, C.; NORD, W. R.
(Orgs.) Handbook de Estudos Organizacionais, v.II, São Paulo: Atlas, 1998.

FLORES-PEREIRA, M. T.; CAVEDON, N. R. Cozinhando as dimensões de estudo dos artefatos organizacionais com novos ingredientes: emoção e embodiment. In: VI Encontro da Divisão de Estudos Organizacionais da ANPAD - EnEO. Florianópolis. Anais... Rio de Janeiro: ANPAD, 2010.

FORD, J.; HARDING, N. Fear and loathing in Harrogate, or a study of a conference.

Organization, v. 15, n. 2, p. 233-250, 2008.

FOUCAULT, M. Segurança, Território e População. São Paulo: Martins Afonso, 2008.

GUERARDI, S. Introduction: the critical power of the "practice lens". Management Learning, v. 40, n. 2, p. 115-128, 2009.

HERZFELD, M. The cultural politics of gesture: Reflections on the embodiment of ethnographic practice. Ethonography, v.10, n.2, p. 131-152, 2009.

HOCHSCHILD, A. R. Emotion work, feeling rules and social structure. American Journal of Sociology, v. 85, p. 551-575, 1979.

The Managed Heart: commercialization of human feeling. Berkeley: University of California Press, 1983.

KOURY, M. G. P. As ciências sociais das emoções: um balanço. Revista Brasileira de Ciências Sociologia das Emoções, v. 5, n.14/15, p.137-157, 2006.

\section{LE BRETON, D. As Paixões Ordinárias:} antropologia das emoções. Rio de Janeiro: Ed. Vozes, 2009.

LUTZ, C.; ABU-LUGHOD, L. (orgs.). Language and the Politics of Emotion. Cambridge: Cambridge University Press, 1990.

MARQUES, G. A frustração profissional e a lei. Tempo Social: Revista de Sociologia da USP, v. 22, n. 1, p. 127-147, 2010.

MAUSS, M. A expressão obrigatória de sentimentos. In: CARDOSO-DE-OLIVEIRA, R. (org.). Marcel Mauss. São Paulo, Ática, 2003.

MOREIRA, D. A. O método fenomenológico na 
pesquisa. São Paulo: Pioneira Thomson, 2002.

OLIVEIRA, J. S.; CAVEDON, N. R. As tramas políticas emocionais na gênese de processos organizativos em uma organização circense. In: Encontro da Anpad, 36, 2012, Rio de Janeiro.

Anais... Rio de Janeiro: ANPAD, 2012.

PESTANA, F. N.; SAUERBRONN, J. F. R.; MORAIS, F. Reforma administrativa do Estado e trabalho emocional - um estudo a respeito da gestão das emoções realizada por servidores do INSS.

Revista Brasileira de Sociologia da Emoção, v.10, p. 532-565, 2011.

REZENDE, C. B. Um estado emotivo: representação da gravidez na mídia. Cadernos Pagu, v.36, p.315-344, 2011.

ROULEAU, L. Emoção e repertories de gênero nas organizações. In: DAVEL, E.; VERGARA, S. Gestão com pessoas e subjetividade. São Paulo: Atlas, 2009.

SANDERS, P. Phenomenology: A New Way of Viewing Organizational Research. Academy of Management Review, v. 7, n. 3, p. 353-360, 1982.

SHIER, M. L.; GRAHAM, J. R. Work-related factors that impact social work practitioners subjective well-being: Well-being in the workplace. Journal of Social Work, v. 11, p. 4, p. 402-420, 2010.

VILELA, L. V. O. ; ASSUNÇÃO, A. A.

Trabalho emocional: o caso dos trabalhadores de teleatendimento. Cadernos de Psicologia Social do Trabalho (USP), v. 10, p. 81-93, 2007.

VILLARDI, B. Q. Aprendizagem Coletiva n uma IES privada: Um arcabouço analítico dos microprocessos de emocionalidade e poder dos docentes que ensinam e pesquisam na graduação. In: XXXIII Encontro da Anpad, 33, 2009, Rio de Janeiro. Anais... Rio de Janeiro: ANPAD, 2009.

YAKHLEF, A. The corporeality of practice-based learning. Organizations Studies, v. 31, n.4, p. 409430, 2010.

\section{Notas}

${ }^{1}$ Portaria Secretaria de Inspeção do Trabalho / Departamento de Segurança e Saúde no Trabalho no 8 de 30.03.2007 publicada no Diário Oficial da União de 02 de abril de 2007. 